\title{
Neurological recovery, mortality and length of stay after acute spinal cord injury associated with changes in management
}

\author{
CH Tator ${ }^{1}$, EG Duncan ${ }^{1}$, VE Edmonds ${ }^{1}$, LI Lapczak ${ }^{1}$ and DF Andrews ${ }^{2}$ \\ ${ }^{1}$ Spinal Cord Injury Treatment, Research and Prevention Centre, Toronto Hospital; ${ }^{2}$ Department of Statistics, \\ University of Toronto, Toronto, Ontario, Canada
}

Based on epidemiological data from two populations of patients with acute spinal cord injury (ASCI), three outcome measures were compared to evaluate the effectiveness of management of ASCI patients in a regional, specialized acute spinal cord injury unit (ASCIU). The two populations consisted of a pre-ASCIU group of 351 patients managed from 1947-73 before the establishment of the ASCIU, and an ASCIU group of 201 patients managed in an ASCIU from 1974-81. The three outcome measures were mortality rate, length of stay (LOS) during first hospitalization, and neurological recovery. Linear regression and multiple regression analyses were used to determine whether differences in the outcome measures were attributable to differences in admission variables in addition to the influence of the ASCIU.

The results showed that the patients treated in the ASCIU had a significant reduction in the mortality rate of almost $50 \%(P=0.022)$, a significant reduction in the LOS of almost $50 \%(P<0.001)$, and a significant increase in neurological recovery consisting of a doubling of the neurological recovery scale utilized $(P<0.001)$. Multiple regression analysis showed that the reduction in mortality rate was significantly influenced by differences in the admission variables between the two groups. However, the establishment of the ASCIU was associated with a significant reduction in LOS and a significant improvement in neurological recovery. Thus, these results support the view that management of ASCI patients in a regional, multidisciplinary unit is medically advantageous and can reduce the LOS.

Keywords: spinal cord injury; management; recovery; mortality; length of stay

\begin{abstract}
Introduction
The use of tertiary, regional centers can lead to improved outcome because regional units make possible the assembly of personnel with specialized training and specialized technology providing a multidisciplinary approach. For conditions with a low incidence, the larger numbers of patients managed in these centers permit the staff to develop greater expertise. Since the treatment of complex conditions often requires specialized equipment and highly trained personnel, the concentration of such patients allows more cost effective use of resources. Furthermore, it can be reasoned that concentration provides adequate numbers of patients for clinical trials to advance the field. One of the first regionalized, medical services in the field of spinal cord injury was developed during World War II when Guttmann established a spinal injuries unit at Stoke Mandeville Hospital, England. ${ }^{1}$ Shortly after this, Lyndhurst Lodge was opened in Canada and since
\end{abstract}

Correspondence: $\mathrm{CH}$ Tator MD, Toronto Western Division, Toronto Hospital, McLaughlin Pavilion 2-435, 399 Bathurst Street, Toronto, Ontario M5T 2S8, Canada then, numerous other spinal units have opened mainly for the rehabilitation phase of care.

In Canada, a detailed examination of the management of patients with acute spinal cord injury (ASCI) in Ontario was conducted by Botterell $e t a l^{2}$ for the years 1969 and 1970 . They concluded that '... the system in place, from evacuation and resuscitation to the end of primary rehabilitation, was fragmented and did not ensure that these patients received optimal treatment.' Due partly to this report an acute spinal cord injury unit (ASCIU) was established at Sunnybrook Medical Centre, Toronto, in 1974, the first such regional, multidisciplinary unit in Canada. The present report examines the effectiveness of this unit by assessing the outcome of 201 patients with ASCI admitted to the ASCIU and comparing them with 351 patients treated in two Toronto hospitals prior to the establishment of the ASCIU. To assess the comparability of these two groups of patients their epidemiological features were examined in our recently published report by comparing 11 admission variables. ${ }^{3}$ The present report compares three outcome measures in the two study groups: length of stay (LOS); mortality during the first hospitalization; and neurological recovery after 
extended follow-up. Although there are now several ASCIU's in the United States and in many other countries, there have been very few analyses of their effectiveness as compared with non-ASCIU management, especially in relationship to variations in admission variables. ${ }^{4-7}$ While previous reports have documented benefits in units specializing in the rehabilitation phase of care ${ }^{1-7}$ the necessity of examining the effectiveness of an ASCIU was underlined by the report in 1989 by Heinemann et al $^{4}$ which stated that for acute spinal cord injuries the 'benefits of the specialized unit concept remain largely theoretical'.

\section{Patients and methods}

\section{Study groups}

A total of 552 patients with ASCI originating from the province of Ontario, Canada, between 1947 and 1981 were divided into two groups. The ASCIU group comprised patients selected from the first 220 consecutive admissions to the ASCIU at Sunnybrook Medical Centre from the time of its establishment in 1974 until 1981. For inclusion a patient must have been admitted within 30 days following closed spinal cord injury and have received no definitive management of the ASCI at another institution prior to transfer to the ASCIU. Patients with penetrating injuries (predominantly gunshot wounds), those with injuries below the L2 level or with spinal column injury without cord involvement or with nerve root involvement only, were excluded. Of the 220 ASCI patients, 201 were eligible for entry into the ASCIU group.

Patients in the pre-ASCIU group were admitted to the Toronto General Hospital or to the Sunnybrook Medical Centre during the 26 year period from 1947 to 1973 . For inclusion in the pre-ASCIU group the patient's records must have contained complete documentation of the spinal column injury, cord injury, associated injuries, treatment, and neurological status at the time of discharge. Otherwise, selection criteria were identical to those for the ASCIU group. In all, 351 patients were included in this group. Excluded from both study groups were patients with ASCI who died at the accident scene, or during transfer to hospital, or who were dead-on-arrival at the hospital.

\section{Admission variables}

For both groups, eleven admission variables were examined: age, sex, incidence of pre-existing spinal abnormalities, type of accident, distance from accident site to a study hospital, time interval from accident to admission to a study hospital, level and severity of cord injury, level and type of vertebral column injury, and incidence of non-spinal injuries. These are described in detail in our recently published report. ${ }^{3}$ There were no significant differences between the two groups in frequency of cervical, thoracic and thoracolumbar injuries which were approximately $60 \%, 18 \%$ and $22 \%$ in the two groups, respectively. ${ }^{3}$

Injuries to the vertebral column were classified into six main types according to a previously published method. ${ }^{8}$ The first type was labelled 'normal' and included those cases in which radiological studies failed to show any evidence of trauma, although in some there was a pre-existing condition such as cervical spondylosis. The remaining five types included the following: dislocations, fracture-dislocations, compression fractures, burst fractures, and minor fractures such as fracture of the spinous or transverse processes. The incidence of the various types of fractures was given in the recent report referred to above. ${ }^{3}$

For classification of the severity of the cord injury the previously published 10 point Spinal Cord Injury Severity Scale was used: ${ }^{9}$ Grade 1 -complete cord injury with no preservation of motor or sensory function below the level of the lesion; grades 2 to 9 -decreasing severity of incomplete cord injury (eg, a grade 7 patient has sufficient strength to walk); and Grade 10-normal motor and sensory function (Table 1). Patients graded 10 on admission usually had cord concussion with neurological deficits which resolved during the interval between the accident and admission to hospital. The scoring was based on the initial neurological examination findings of the attending physicians and surgeons.

Many patients in both groups had injuries to other body regions, and an anatomical injury severity score based on that of Baker et al ${ }^{10}$ was used to quantify the total trauma burden. Each patient's spinal and nonspinal injuries were recorded and an injury severity score (ISS) was calculated based on the abbreviated method of Greenspan et al. ${ }^{11}$

\section{Outcome parameters}

For both groups three outcome parameters were assessed: mortality rate; length of hospitalization (LOS); and neurological recovery. LOS and mortality rate were recorded for the first admission to the study hospital. Neurological recovery was analyzed using the

Table 1 Spinal cord injury severity scale

\begin{tabular}{cl}
\hline Grade & Neurological features \\
\hline 1 & Complete motor loss, complete sensory loss \\
2 & Complete motor loss, incomplete sensory loss \\
3 & Incomplete motor useless, ${ }^{\text {a complete sensory loss }}$ \\
4 & Incomplete motor useless, incomplete sensory loss \\
5 & Incomplete motor useless, normal sensory \\
6 & Incomplete motor useful, b complete sensory loss \\
7 & Incomplete motor useful, incomplete sensory loss \\
8 & Incomplete motor useful, normal sensory \\
9 & Normal motor, incomplete sensory loss \\
10 & Normal motor, normal sensory \\
\hline
\end{tabular}

aUseless is defined as the retention of some motor power (grades 1 or 2 on the Medical Research Council Scale) below the level of the lesion but which is insufficient to be of practical use to the patient

bUseful is defined as the retention of sufficient voluntary power (grades 3-5 on the Medical Research Council Scale) to be of practical use to the patient 
previously published 17-point Cord Injury Neurological Recovery Index,${ }^{9}$ which scored recovery or deterioration for each patient by comparing the neurological grade at admission with that at the end of the follow-up period. With the Recovery Index (Table 2) patients with neurological grade 1 could potentially improve by a maximum of eight change values, from neurological change value 9 to 17. Thus a grade 1 patient achieving the maximum possible improvement would be scored as $100 \%$ neurological recovery. A grade 2 patient who recovered to grade 4 by regaining some distal motor function of less than MRC grade 3 strength would be considered to have improved to value 14 (Table 2) which represents an improvement of five of a possible eight values for a $62.5 \%$ neurological recovery. $\mathrm{Pa}$ tients who showed no recovery are scored as $0 \%$, and those with neurological deterioration are scored as negative percentages.

In the pre-ASCIU group the follow-up period was 12 months for patients with complete cord injuries and 18 months for incomplete injuries. However, analysis of this group showed that no new neurological improve-

Table 2 Spinal cord injury neurological recovery index

\begin{tabular}{|c|c|}
\hline $\begin{array}{l}\text { Neurological } \\
\text { change- } \\
\text { numerical } \\
\text { value }\end{array}$ & Description of neurological change \\
\hline 1 & $\begin{array}{l}\text { Deterioration to complete motor, complete } \\
\text { sensory loss }\end{array}$ \\
\hline 2 & $\begin{array}{l}\text { Deterioration to complete motor, incomplete } \\
\text { sensory loss }\end{array}$ \\
\hline 3 & $\begin{array}{l}\text { Deterioration to incomplete motor, complete } \\
\text { sensory loss }\end{array}$ \\
\hline 4 & $\begin{array}{l}\text { Deterioration to incomplete motor, } \\
\text { incomplete sensory loss }\end{array}$ \\
\hline 5 & $\begin{array}{l}\text { Deterioration to incomplete motor, normal } \\
\text { sensory }\end{array}$ \\
\hline 6 & $\begin{array}{l}\text { Deterioration to normal motor, incomplete } \\
\text { sensory loss }\end{array}$ \\
\hline 7 & $\begin{array}{l}\text { Deterioration to higher level, but grade }{ }^{a} \text { the } \\
\text { same }\end{array}$ \\
\hline 8 & $\begin{array}{l}\text { Deterioration at same level, but grade the } \\
\text { same }\end{array}$ \\
\hline 9 & No change \\
\hline 10 & $\begin{array}{l}\text { Improvement at same level, but grade } \\
\text { unchanged }\end{array}$ \\
\hline 11 & $\begin{array}{l}\text { Improvement to lower level, but grade } \\
\text { unchanged }\end{array}$ \\
\hline 12 & $\begin{array}{l}\text { Improvement to complete motor, incomplete } \\
\text { sensory loss }\end{array}$ \\
\hline 13 & $\begin{array}{l}\text { Improvement to incomplete motor, complete } \\
\text { sensory loss }\end{array}$ \\
\hline 14 & $\begin{array}{l}\text { Improvement to incomplete motor, } \\
\text { incomplete sensory loss }\end{array}$ \\
\hline 15 & $\begin{array}{l}\text { Improvement to incomplete motor, normal } \\
\text { sensory }\end{array}$ \\
\hline 16 & $\begin{array}{l}\text { Improvement to normal motor, incomplete } \\
\text { sensory loss }\end{array}$ \\
\hline 17 & Improvement to normal \\
\hline
\end{tabular}

aSee Table 1 ment below the level of the injury began after 6 months for patients with complete injuries or after 12 months for those with incomplete injuries, and that any additional recovery after these times did not alter the assigned neurological recovery score. ${ }^{8,9}$ Therefore, these shorter follow-up times were applied to the ASCIU group. Follow-up neurological status was primarily assessed by personal outpatient review by the admitting surgeon, but in some cases by specialists, mainly in physical medicine and rehabilitation, or general practitioners involved in ongoing supervision of the patient, or by contacting the patient or a surviving relative directly.

\section{Data analysis}

Data for both groups, collected prospectively from the time of admission for the ASCIU group and retrospectively from medical records for the pre-ASCIU group, were coded for computer entry using standardized coding sheets and initially processed at the University of Toronto Computer Centre using the Statistical Package for the Social Sciences (SPSS). Final analysis was performed with the Statistical Analysis Systems software package for PC (SAS, Cary, NC, USA). The outcome parameters for the two study groups were compared using the $\chi^{2}$ test and two-tailed $t$ test for discrete and continuous variables, respectively. Further statistical analysis using linear regression and stepwise multiple regression techniques were also employed. In all statistical analyses a result was considered significant if a significance level of $P<0.05$ was achieved.

\section{Results}

\section{Summary of epidemiological analysis}

A total of 552 patients were entered into the study, 351 in the pre-ASCIU group and 201 in the ASCIU group. Details of the epidemiological features of these patients including age, sex, pre-existing spinal abnormalities, type of accident, delay from accident to admission to study hospital, level of spinal injury, type of vertebral fracture, severity of cord injury, and severity of associated, non-spinal injuries are contained in the recently published companion report, ${ }^{3}$ and therefore only a brief summary of the findings is provided here. In both groups, approximately $80 \%$ of the patients were male and $20 \%$ female, and the sex ratio was similar for both groups $\left(\chi^{2}, P=0.61\right)$. The median age in the pre-ASCIU group was 32.0 and in the ASCIU group 27.0 years, although this difference was not significant (two-tailed $t$ test, $P=0.076$ ). In the ASCIU group there was a significantly higher frequency of motor vehicle and sport-recreational accidents, and a lower frequency of work related injuries as compared to the pre-ASCIU group $\left(\chi^{2}, P=0.001\right)$. The ASCIU group was admitted to the study hospital much sooner after injury than the pre-ASCIU group with the time interval from accident to admission to a study hospital decreasing from a median time of $13 \mathrm{~h}$ to $5 \mathrm{~h}$ (two-tailed $t$ test, $P<0.001)$. A pre-existing spinal abnormality 
was found in approximately $16.5 \%$ of cases with a similar incidence in both groups $\left(\chi^{2}, P=0.91\right)$, and in both the most common pre-existing abnormality was cervical spondylosis. In both groups about $60 \%$ of the spinal injuries were at the cervical level $\left(\chi^{2}, P=0.32\right)$. The level of the spinal cord injury and the level of the most significant vertebral column injury were identical in most patients and, therefore, the same level was used to describe both. There were highly significant differences between the two groups in the types of spinal column injuries $\left(\chi^{2}, P=0.001\right)$ : in the ASCIU group there were lower frequencies of dislocation, fracturedislocation, compression fracture or normal radiographs as compared to the pre-ASCIU group, but a much higher frequency of burst fracture. The incidence of complete cord injury significantly decreased from $65 \%$ in the pre-ASCIU group to $46 \%$ in the ASCIU group (two-tailed $t$ test, $P<0.001$ ). The total trauma burden, summarized as an ISS was reduced from a mean of 26.7 in the pre-ASCIU group to 24.8 in the ASCIU group, a small but significant difference (twotailed $t$ test, $P=0.015$ ) due to the reduced severity in the ASCIU group of the spinal cord injury itself, a component of the ISS.

\section{Outcome measures}

In the pre-ASCIU and ASCIU groups 20 (5.6\%) and eight $(4.0 \%)$ patients, respectively, were lost to follow-up. Many of these patients had minor cord injuries and lived in areas remote from the study hospitals, some being foreign visitors. Therefore, the analyses requiring data obtained at follow-up were based on only 524 patients. For the analyses of LOS and mortality, data was available for the total study population of 552 patients.

Length of stay In the pre-ASCIU group, the mean LOS was 86.9 days while the mean LOS for the ASCIU group was 48.2 days, a highly significant difference (two-tailed $t$ test, $P<0.001$ ).

Mortality rate In the pre-ASCIU group, 49 patients (14\%) died during first hospitalization as compared to 15 patients $(7.5 \%)$ in the ASCIU group, a significant reduction $\left(\chi^{2}, P=0.022\right)$ (Table 3$)$. Table 3 also shows the relationship between the severity of the ASCI and the mortality rate. There was a marked reduction in the death rate for patients with complete ASCI, from $22.1 \%$ in the pre-ASCIU group to $12.1 \%$ in the ASCIU group. There was also a slight decline in the death rate for incomplete SCI from $10.1 \%$ in the pre-ASCIU group to $7.8 \%$ in the ASCIU group. Indeed, in the ASCIU group the death rate for complete and incomplete ASCI was almost the same $\left(\chi^{2}, P=0.32\right)$, whereas in the pre-ASCIU group the difference in survival between patients with complete and incomplete ASCI was significant $\left(\chi^{2}, P=0.003\right)$.

LOS and mortality were significantly related only in the pre-ASCIU group in which the mean LOS for patients alive at first discharge was 97.3 days whereas it was 22.7 days for patients dying during the first admission, a highly significant difference (two-tailed $t$ test, $P<0.001)$. Such a relation was not seen in the ASCIU group in which survivors and non-survivors at first discharge had mean LOS of 48.9 days and 40.4 days respectively, which were not significantly different (two-tailed $t$ test, $P=0.43$ ).

Table 3 Mortality rates for each study group

\begin{tabular}{|c|c|c|c|c|c|c|}
\hline & \multicolumn{2}{|c|}{ Pre-ASCIU } & \multicolumn{2}{|c|}{$A S C I U$} & \multicolumn{2}{|c|}{ Total } \\
\hline & $n^{a}$ & $\%$ & $n$ & $\%$ & $n$ & $\%$ \\
\hline \multicolumn{3}{|c|}{ (a) Deaths classified by time of death } & & & & \\
\hline Number of deaths & 49 & 14.0 & 15 & 7.5 & 64 & 11.6 \\
\hline Death during follow-up & \multicolumn{2}{|c|}{$n=331$} & \multicolumn{2}{|c|}{$n=193$} & \multicolumn{2}{|c|}{$n=524$} \\
\hline Number of deaths & 11 & 3.3 & 4 & 2.1 & 15 & 2.9 \\
\hline Total deaths & \multicolumn{2}{|c|}{$n=331$} & \multicolumn{2}{|c|}{$n=193$} & \multicolumn{2}{|c|}{$n=524$} \\
\hline Number of deaths & 60 & 18.1 & 19 & 9.8 & 79 & 15.1 \\
\hline \multicolumn{7}{|c|}{ (b) Deaths classified by severity of cord injury } \\
\hline $\begin{array}{l}\text { Complete injury } \\
\text { (Grade 1) }\end{array}$ & \multicolumn{2}{|c|}{$n=215$} & \multicolumn{2}{|c|}{$n=91$} & & \\
\hline Number of deaths & 49 & 22.1 & 11 & 12.1 & 60 & 18.1 \\
\hline $\begin{array}{l}\text { Incomplete injury } \\
\text { (Grades } 2-10 \text { ) }\end{array}$ & \multicolumn{2}{|c|}{$n=116$} & \multicolumn{2}{|c|}{$n=102$} & & \\
\hline Number of deaths & 11 & 10.1 & 8 & 7.8 & 19 & 9.8 \\
\hline Total deaths & \multicolumn{2}{|c|}{$n=331$} & \multicolumn{2}{|c|}{$n=193$} & \multicolumn{2}{|c|}{$n=524$} \\
\hline Number of deaths & 60 & 18.1 & 19 & 9.8 & 79 & 15.1 \\
\hline
\end{tabular}

${ }^{\text {a }} n=$ number of available patients (see text for explanation) 
To examine the influence of mortality, LOS was also analyzed with the exclusion of patients who died during the first hospitalization. The mean LOS for the 302 patients in the pre-ASCIU group and the 186 patients in the ASCIU group who survived to first discharge was 97.3 days and 48.9 days, respectively, a difference which remained highly significant (two-tailed $t$ test, $P<0.001)$.

Neurological recovery Patients lost to follow-up before completion of the full follow-up period as defined above, were excluded from this analysis. Also excluded were the 69 patients in the pre-ASCIU group, and the 19 patients in the ASCIU group, who died prior to the completion of follow-up. Thus, for the analysis of neurological recovery only patients alive and available for review at the end of full follow-up were included which totalled 262 patients in the pre-ASCIU group and 173 patients in the ASCIU group. Recovery was determined by calculating the change in neurological status based on the 17-point Cord Injury Neurological Recovery Index (Table 2 ). The mean \% recovery was $28.8 \%$ for the ASCIU group compared with a mean of $13.0 \%$ in the pre-ASCIU group, a highly significant difference (two-tailed $t$ test, $P<0.001$ ).

\section{Effect on outcome measures of epidemiological differences between the study groups}

Table 4 shows the analyses to study the extent to which the differences in the outcome measures were associated with the significant variations between the two groups in epidemiologic features including accident type, delay from accident to admission to a study hospital, severity of ASCI and severity of combined injuries (ISS), in addition to changes in management. Separate multiple regression analyses were performed for each of the outcome measures (LOS, mortality and neurological recovery) as the dependent variable and nine admission variables (age, sex, presence of preexisting spinal abnormality, type of accident causing injury, interval from trauma to admission to a study hospital, neurological grade on admission, level of cord injury and ISS) as the independent variables. Separate multiple regression analyses were performed for the pre-ASCIU group, the ASIU group and the combined population. In the analyses for the total population a variable which indicated study group (pre-ASCIU or ASCIU) was included as an independent variable to assess management. The appearance of this variable, study group, in the final list of independent variables indicates a significant correlation between study group and that outcome variable.

Table $4 \mathrm{a}$ shows the results of the multiple regression analysis for mortality rates for the total study population and for each of the two study groups. For the pre-ASCIU and ASCIU groups, and for the total population, the mortality rate was shown to be dependent on both age and ISS with mortality increasing with increasing age and increasing ISS. These relationships were highly significant $(P=0.0001)$. In the pre-ASCIU and total groups there was also a highly significant relationship between mortality rate and level of ASCI with mortality increasing with more cephalad injuries. This relationship was not seen in the ASCIU group. However, there was a statistically significant association between sex and mortality in the ASCIU group with males having a higher mortality rate than females. When the association between sex and mortality was examined directly, no statistically significant result was found $\left(\chi^{2}, P=0.25\right)$. Further analysis failed to reveal any significant correlation between sex and other admission variables, such as age, level or severity of cord injury, for the ASCIU group which might have contributed to the observed association of mortality and sex in this group.

The results of the multiple regression analysis for LOS are presented in Table $4 b$ and c. When LOS for the whole population was examined, management in the ASCIU was associated with a shorter stay (study group, Table $4 \mathrm{~b}$ ) and the association was highly significant $(P=0.0001)$. For the pre-ASCIU arid total groups, LOS was dependent upon the level and severity of the cord injury and the age and sex of the patient. LOS was increased for more severe and for more caudal injuries, and younger and male patients.

As noted previously, mortality and LOS were related in the pre-ASCIU and total patient groups. Therefore, to examine factors other than mortality which influenced LOS, the multiple regression analysis was repeated using only the patients alive at first discharge (Table 4c). For the total group, management in the ASCIU remained a significant factor in determining LOS. For all three patient groups, increasing severity of ASCI remained significantly correlated with longer LOS. The effect of age on LOS was not significant among only those patients who were alive at first discharge. Of note is that with the ASCIU group of patients who survived to first discharge, an increased delay from accident to admission to the unit was associated with an increased LOS.

The results of the mulitiple regression analysis of neurological recovery are shown in Table 4d. Higher neurological recovery was strongly associated with less severe ASCI and less total trauma burden (ISS). Improved neurological recovery was also associated with management in the ASCIU (study group, Table $4 d$ ) and with more cephalad injuries. The effect of level of injury on neurological recovery appears to have been mediated through ISS, which showed a high correlation with level of injury (ISS increased with more caudal injuries, correlation $P=0.0009$ ). There was not a significant correlation between severity of ASCI and anatomic level of injury (correlation, $P=0.1571$ ).

\section{Effect of year of admission on outcome measures} Further insight into the relationship between the outcome variables and the establishment of the ASCIU can be obtained by examining trends (linear correlation) in the outcome variables during the periods 1947-1973, 1974-1981 and the whole period 1947-1981. A linear regression equation was calculated for each of the three time periods and each of the three 
Table 4 Multiple regression model of association of mortality rate, LOS, or neurological recovery with admission variables

\begin{tabular}{|c|c|c|c|c|c|}
\hline \multicolumn{6}{|c|}{ Study group } \\
\hline \multicolumn{2}{|l|}{ Pre-ASCIU $(n=351)$} & \multicolumn{2}{|l|}{$A S C I U(n=201)$} & \multicolumn{2}{|l|}{ Total $(n=552)$} \\
\hline \multicolumn{6}{|c|}{ (a) Higher mortality rate (analysis in all patients) } \\
\hline Admission variable & $P$ & Admission variable & $P$ & Admission variable & $P$ \\
\hline $\begin{array}{l}\text { Age }_{\text {(increasing) }} \\
\text { ISS }_{\text {(increasing) }} \\
\text { Level (more cephalad) }\end{array}$ & $\begin{array}{l}0.0001 \\
0.0001 \\
0.0001\end{array}$ & $\begin{array}{l}\text { Age }_{\text {(increasing) }} \\
\text { ISS }_{\text {(increasing) }} \\
\operatorname{Sex}_{\text {(male) }}\end{array}$ & $\begin{array}{l}0.0001 \\
0.0001 \\
0.0200\end{array}$ & $\begin{array}{l}\text { Age }_{\text {(increasing) }} \\
\text { ISS }_{\text {(increasing) }} \\
\text { Level }_{\text {(more cephalad) }}\end{array}$ & $\begin{array}{l}0.0001 \\
0.0001 \\
0.0001\end{array}$ \\
\hline \multicolumn{6}{|c|}{ (b) Higher LOS (analysis in all patients) } \\
\hline Admission variable & $P$ & Admission variable & $P$ & Admission variable & $P$ \\
\hline $\begin{array}{l}\operatorname{Grade}_{(\text {decreasing) }} \\
\text { Level }_{(\text {more caudal) }} \\
\operatorname{Age}_{(\text {decreasing })} \\
\operatorname{Sex}_{(\text {male })}\end{array}$ & $\begin{array}{l}0.0001 \\
0.0001 \\
0.0005 \\
0.0138\end{array}$ & Grade $_{\text {(decreasing) }}$ & 0.0043 & $\begin{array}{l}\text { Study group } \\
\text { Grade }_{\text {(decreasing) }} \\
\text { Level (more caudal) }_{\text {(mole }} \\
\text { Age }_{\text {(decreasing) }} \\
\operatorname{Sex}_{(\text {male })}\end{array}$ & $\begin{array}{l}0.0001 \\
0.0001 \\
0.0001 \\
0.0006 \\
0.0104\end{array}$ \\
\hline Pre-ASCIU $(n=302)$ & & $A S C I U(n=186)$ & & Total $(n=488)$ & \\
\hline
\end{tabular}

(c) Higher LOS (analysis in survivors at first discharge)

$\begin{array}{lclcll}\text { Admission variable } & P & \text { Admission variable } & P & \text { Admission variable } & P \\ \text { Grade }_{\text {(decreasing) }} & 0.0001 & \text { Grade }_{\text {(decreasing) }} & 0.0017 & \text { Study group } & 0.0001 \\ \text { Level }_{\text {(more caudal) }} & 0.0002 & \text { Interval }_{\text {(increasing) }} & 0.0318 & \text { Grade }_{\text {(decreasing) }} & 0.0001 \\ & & & & \text { Level }_{\text {(more caudal) }} & 0.0004 \\ & & & & \text { Sex }_{\text {(male) }} & 0.0384\end{array}$

$\operatorname{Pre}-\operatorname{ASCIU}(n=262) \quad$ ASCIU $(n=173) \quad$ Total $(n=435)$

(d) Higher neurological recovery (analysis in patients with full follow-up)

$\begin{array}{lclc}\text { Admission variable } & P & \text { Admission variable }_{\text {(inde }} & P \\ \text { Grade }_{\text {(increasing) }} & 0.0001 & \text { Grade }_{\text {(increasing) }} & 0.0001 \\ \text { Level }_{\text {(more cephalad) }} & 0.0193 & \text { ISS }_{\text {(decreasing) }} & 0.0139\end{array}$

$\begin{array}{clc}P & \text { Admission variable } & P \\ 0.0001 & \text { Grade }_{\text {(increasing) }} & 0.0001 \\ 0.0139 & \text { Level }_{\text {(more cephalad) }} & 0.0013 \\ & \text { ISS }_{\text {(decreasing) }} & 0.0075 \\ & \text { Study group } & 0.0260\end{array}$

Admission variables entered into (a), (b), (c) and (d):

Age $=$ age direction as indicated

Sex $=$ male or female as indicated

Pre-existing spinal abnormality

Interval $=$ time from accident to admission

Cause $=$ cause of accident

Grade $=$ severity of cord injury (Table 1$)$, direction as indicated

Level = anatomical level of spinal injury as indicated

ISS = severity of combined spinal and non-spinal injuries, direction as indicated

Study group = pre-ASCIU group versus ASCIU group

outcome variables to see how much of the observed changes may be attributed to other unmeasured factors evolving over time. There was no significant linear correlation for LOS when plotted against year for each of the two study groups (pre-ASCIU, $r=0.04$; ASCIU, $r=0.23)$ nor for the combined group $(r=0.29)$ over the total study period from 1947 to 1981 . Indeed, during the pre-ASCIU phase of the study, including the latter years, there is no suggestion of a reduced LOS. Similarly, there was no significant change in LOS for the ASCIU group, during the 1974-1981 interval. However, the significant difference in the LOS noted before was evidenced by the significant discontinuity between the regression lines for the two groups
$(P<0.05)$. This suggests a significant reduction in LOS coincident with the establishment of the ASCIU rather than the continuation of a trend which had existed prior to the opening of the ASCIU.

When the correlations between mortality and year of admission were examined for the entire study period and for the pre-ASCIU and ASCIU groups separately, there was a significant linear correlation between year of admission and mortality for the entire period, with mortality declining steadily throughout the total study period. However, there was no such relationship apparent when the pre-ASCIU and ASCIU periods were examined separately. A pattern similar to that for mortality was found for neurological recovery. 
With both mortality rate and neurological recovery, the pre-existing trends of decreased mortality rate and increased neurological recovery were continued in a beneficial way during the era of the ASCIU.

\section{Discussion}

In the present study, the group managed in a multidisciplinary, regional ASCIU was compared to a historical control group. The ASCIU group had an improved outcome including decreased mortality, decreased LOS, and enhanced neurological recovery, compared with the group of patients with ASCI managed in two Toronto hospitals, both tertiary referral centres, prior to the establishment of the ASCIU. The most robust clinical study designs involve prospective random allocation of similar groups of patients to either treatment or control groups so that significant differences between the groups can be attributed with confidence to the treatment. In the present study it would not have been feasible to randomly allocate the patients to either the ASCIU or another hospital. Therefore, before the improvements in the ASCIU group can be attributed to management in the ASCIU, it is necessary to analyze the design of the present study. Neither the ASCIU group nor the pre-ASCIU group comprised all the patients with ASCI in the overall catchment area of the study hospitals. Furthermore, the two study groups were recruited by different methods, and therefore, represent selected subgroups of patients with ASCI. Fortunately, comparisons can be made with the findings of Botterell et $a l^{2}$ who attempted to identify all patients with ASCI in the province of Ontario in the years 1969 and 1970. They identified 224 patients and reported an annual incidence of 15 per million per year. Comparison of the admission characteristics of the pre-ASCIU group with the 224 patients studied by Botterell et al showed that the two groups were similar, indicating that the pre-ASCIU group is very likely to be representative of all patients with ASCI in the province of Ontario for the years in question. Using the incidence figure of Botterell et al, there being no more recent figure available, we estimate that the pre-ASCIU group comprised on average about $16 \%$ of the province's annual ASCI patients and the ASCIU group comprised on average about $25 \%$. Thus, because both the pre-ASCIU and ASCIU groups comprised similar, representative samples of all the province's ASCI patients and included large numbers, it is unlikely that there was a selection bias resulting in unrepresentative samples. Furthermore, in general, the epidemiological features of both groups are comparable to populations of ASCI patients described by other authors ${ }^{12-16}$ which supports the generalizability of the present findings to ASCI patients in other countries,

The decrease in the mortality rate between the two groups (Table 3) was greatest for complete ASCI, in whom the mortality rate declined by almost $50 \%$ between the two study periods. The multiple regression analysis (Table 4) showed that in both groups mortality was strongly dependent on patient age, with older patients showing an increased mortality rate. This relationship between mortality rate and age has been observed by other authors. ${ }^{5,17,18}$ The level of cord injury correlated significantly with mortality but only in the total and pre-ASCIU groups: patients with more cephalad injuries had a higher mortality rate. Improvement in the prevention and management of respiratory complications in patients with cervical injuries would explain the reduction in mortality rate in the ASCIU group. The reduction in mortality rates in both complete and incomplete injuries has been related by other authors to the development of a system of acute care. ${ }^{17,19}$

Also significant in determining survival after ASCI was the ISS, with increased total trauma load being associated with increased mortality (Table 4). This finding is in agreement with studies of multiple trauma patients in general, ${ }^{20,21}$ but had not been shown specifically for ASCI patients with multiple trauma. In a previous report from this centre describing a subset of ASCI patients we compared 27 patients with multiple trauma to 117 without multiple trauma and found a mortality rate of $19 \%$ in the multiple trauma group and only $4 \%$ in those without multiple trauma. ${ }^{22}$ Similarly, Hachen $^{17}$ and Kiwerski and Weiss ${ }^{18}$ showed increased mortality in ASCI patients who had associated injuries, especially head or chest injuries.

Although the severity, but not the level, of the SCI is reflected in the ISS, any additional, extraspinal injuries also contributed significantly to the eventual outcome. Indeed, the results of the multiple regression analysis (Table 4a) show that ISS was a more sensitive indicator of fatal outcome than the severity of the SCI alone.

The dependence of mortality on the sex of the ASCIU group (Table 4a) is difficult to explain. When examined directly, using the $\chi^{2}$ test, there was no difference in mortality between sexes. Furthermore, when correlations between sex and the other admission variables which might have influenced mortality were obtained, none was significant.

The failure of the study group variable to reach significance in the multiple regression analysis of mortality suggests that the reduction in mortality in the ASCIU group (Table 3) can be explained in part by factors in addition to management in the ASCI. This interpretation is supported by the results of linear regression when mortality rate (as per cent mortality per year) was plotted against year of admission. The results suggest that the reduced mortality was not solely a direct treatment effect of the opening of the ASCIU, but rather was a cumulative effect due to many general improvements in medical care over the whole study period. Indeed, if the average yearly mortality rates are examined, a progressive reduction in mortality rate can be observed which is most likely due to several medical advances which occurred during this era including the introduction of antibiotics, enhanced surgical and anesthetic techniques, and in particular, the development of effective mechanical ventilation which has enhanced the survival of patients with cervical spinal 
cord injury or concomitant thoracic injury. This interpretation is supported by the reduced mortality of patients with cervical injuries in the ASCIU group. Thus, the reduction in mortality in the ASCIU group is due to many factors, especially the reduction of complications.

The LOS decreased by almost $50 \%$ in the ASCIU group, and the multiple regression analysis showed that the severity of the ASCI was an important factor influencing this outcome (Table $4 b, c)$. For the preASCIU group, level of injury, age and sex were also significant variables. The most significant variable in the multiple regression analysis of LOS for the total population of patients was the study group (Table $4 \mathrm{~b}, \mathrm{c})$ consistent with the view that innovations in management by the ASCIU reduced hospitalization time. This interpretation is supported by the finding that for the ASCIU group, delay from accident to admission was associated with LOS, with patients admitted at longer intervals after injury having a longer LOS (Table 4c).

There are two principal reasons to explain the relationship between LOS and the vertebral level of the injury: there were more associated injuries to the chest and abdomen in patients with more caudal injuries; and many of the thoracic and lumbar injuries required longer periods of bed rest to achieve spinal stability which often delayed transfer to a rehabilitation facility.

The results of the linear regression analysis of LOS against year of admission showed differences coincident with the establishment of the ASCIU. During the 1947-73 period of the pre-ASCIU group there was no significant trend towards a reduction in the LOS. However, in the ASCIU period there was an immediate and sustained reduction in LOS. Other factors also contributed to this effect, including the reduced severity of ASCI in the ASCIU group, but management in the ASCIU was an important factor as supported by the finding that study group was the most significant variable in the multiple regression analysis (Table 4b,c). Throughout the 1947 to 1981 study period almost all patients were discharged to Lyndhurst Hospital in Toronto for rehabilitation, and there were no significant changes in Lyndhurst's admission policies during the study period which may have resulted in earlier admission to Lyndhurst. It is noteworthy that ASCI patients referred to Lyndhurst from other hospitals during 1974-81 had a much longer LOS in those other hospitals than in the ASCIU. ${ }^{23}$ As shown in another recently published companion study the major reason for the reduced LOS in the ASCIU group was the reduction in complications. ${ }^{24}$ Heinemann et al ${ }^{4}$ also found a decreased LOS in the acute phase for patients treated initially in an ASCIU.

The extent of neurological recovery was significantly greater in the ASCIU group as compared to the pre-ASCIU group and the multiple regression analysis identified that the three most significant factors influencing neurological recovery were the level and severity of the SCI and the ISS (Table 4d). It is felt that the main factor accounting for the improved neurological function in the ASCIU group was the reduced severity of SCI, since it is well known that an incomplete SCI has much more potential for recovery than a complete lesion. 5,25 This interpretation is supported by the highest significance associated with neurological grade on admission in the multiple regression analysis.

The effect of level of spinal injury in neurological recovery appears to be mediated through the effect of level of injury on ISS. For the pre-ASCIU and total groups there was a significant correlation between the level of injury and the ISS, with the ISS increasing with more caudal injuries. This is consistent with fractures to the thoracic and thoracolumbar spine being associated with more severe accidents such as motor vehicle and work related injuries which tend to cause more associated injuries than do sports or domestic accidents. The effect of ISS on neurological recovery is more difficult to explain. It may reflect that the SCI component was the largest single value contributing to the total ISS in the present group of patients, and thus, the ISS exerts its effect on the basis of the severity of SCI. It is also possible that patients with more severe associated injuries had less neurological recovery because they may have suffered additional cord damage from systemic hypoxia or hypotension due to their more extensive non-spinal injuries. It is noteworthy that in our previous study referred to above on a subset of the same patients, $30 \%$ of ASCI patients with multiple trauma had a systolic pressure of $70 \mathrm{~mm} \mathrm{Hg}$ or less on admission as compared with $2 \%$ of ASCI patients without multiple trauma. ${ }^{22}$

Examination of neurological recovery against the year of admission showed fewer mean scores with deterioration in neurological status in the ASCIU group than in the pre-ASCIU group. Preservation of the neurological function present at admission by prevention of secondary deterioration is a paramount goal in management. Our findings are consistent with the view that the newer treatment regimes possible in multidisciplinary centres contribute to improved recovery (Table 4d).

The dependence of mortality and neurological recovery on ISS is an important consideration for the management of patients with multiple trauma and for the development of future clinical trials of treatment of ASCI. Patients presenting with multiple injuries associated with ASCI require more aggressive management to reduce the mortality and improve the neurological outcome. Indeed, studies of the management of ASCI should incorporate in the study design and statistical analysis methods to accommodate differences in total trauma burden between study groups.

There were some admission variables which did not effect the outcome measures as shown by multiple regression analysis (Table 4). For example, the type of accident causing the ASCI did not appear to influence any of the outcome parameters, although the influence of this factor may have been reflected in other variables such as age, ISS or level of injury. The interval from trauma to admission was associated with LOS in the ASCIU group, but did not appear significantly to 
influence either mortality or neurological recovery, although it might have been expected that early referral and admission to a specialist ASCIU would have effected these results. Kiwerski and Weiss ${ }^{18}$ found a higher frequency of neurological improvement in patients admitted to their specialized unit within $24 \mathrm{~h}$ of injury. Also, experimental studies of animal models of ASCI have shown that early treatment influenced outcome. $^{26,27}$ However, the lack of effect of early admission on neurological recovery is in agreement with our previous study ${ }^{28}$ in the ASCIU group in which surgical decompression, however expeditious, did not improve neurological recovery.

These results suggest that outcome from ASCI can be optimized by early referral to an ASCIU with a multidisciplinary surgical, medical, nursing and paramedical staff possessing specialized training in the diagnosis and treatment of the acute phase of spinal cord injury including the initiation of rehabilitation measures as soon as possible after admission. It has been estimated that an ASCIU should treat a minimum of 25 new patients per year to establish and maintain proficiency. ${ }^{29,30}$

\section{Acknowledgements}

This study was supported by a Demonstration Model Grant from the Ontario Ministry of Health and by a Sustaining Grant from the Canadian Paraplegic Association, Ontario Branch. The authors are grateful to Ms Sandi Amaral and Ms Maria Vespa for technical assistance.

\section{References}

1 Guttmann L. History of the National Spinal Injuries Centre, Stoke Mandeville Hospital, Aylesbury. Paraplegia 1967; 5: 115-126.

2 Botterell EH et al. A model for the future care of acute spinal cord injuries. Ann R Coll Phys Surg Can 1975; 8: 193-218.

3 Tator $\mathrm{CH}$ et al. Epidemiological changes in acute spinal cord injury: analysis of 552 patients from 1947 to 1981. Surg Neurol 1993; 40: 207-215.

4 Heinemann AW et al. Functional outcome following spinal cord injury. A comparison of specialized spinal cord injury center $v s$ general hospital short-term care. Arch Neurol 1989; 46: 1098-1102.

5 Kiwerski J, Weiss M. Neurological improvement in traumatic injuries of cervical spinal cord. Paraplegia 1981; 19: 31-37.

6 Meyer PR Jr, Sullivan DO. Injuries to the spine. Emerg Med Clin North Am 1984; 2: 313-329.

7 Yarkony GM, Bass LM, Keenan V, Meyer PR. Contractures complicating spinal cord injury: incidence and comparison between spinal cord centre and general hospital acute care. Paraplegia 1985; 23: 265-271.

8 Tator $\mathrm{CH}$. Spine-spinal cord relationships in spinal cord trauma. Clin Neurosurg 1983; 30: 479-494.
9 Tator CH, Rowed DW, Schwartz ML. Sunnybrook cord injury scales for assessing neurological injury and neurological recovery. In: Tator CH (ed). Early Management of Acute Spinal Cord Injury. Raven Press: New York, 1982, pp 7-24.

10 Baker SP, O'Neill B, Haddon W, Long WB. The injury severity score: a method for describing patients with multiple injuries and evaluating emergency caré. J Trauma 1974; 14: 187-196.

11 Greenspan L, McLellan BA, Greig H. Abbreviated injury scale and injury severity score: a scoring chart. J Trauma 1985; 25: 60-64.

12 Gjone R, Nordlie L. Incidence of traumatic paraplegia and tetraplegia in Norway: a statistical survey of the years 1974 and 1975. Paraplegia 1978-79; 16: 88-93.

13 Kraus JF. Injury of the head and spinal cord. The epidemiological relevance of the medical literature published from 1960 to 1978. J Neurosurg 1980; 53: S3-S10.

14 Kraus JF et al. Incidence of traumatic spinal cord lesions. J Chron Dis 1975; 28: 471-492.

15 Kurtzke JF. Epidemiology of spinal cord injury. Exp Neurol 1975; 48: 163-236.

16 Minaire $\mathrm{P}$ et al. Epidemiology of spinal cord injury in the Rhone-Alpes Region, France, 1970-75. Paraplegia 1978-79; 16: $76-87$.

17 Hachen HJ. Idealized care of the acutely injured spinal cord in Switzerland. J Trauma 1977; 17: 931-936.

18 Kiwerski J, Weiss M, Chrostowska T. Analysis of mortality of patients after cervical spine trauma. Paraplegia 1981; 19: 347-351.

19 Harris $\mathrm{P}$ et al. The prognosis of patients sustaining severe cervical spine injury (C2-C7 inclusive). Paraplegia 1980; 18: 324-330.

20 Burns CM. Accident-injury organization: Canadian overview. Can J Surg 1985; 28: 482-485.

21 Wright CS, McMurtry RY, Hoyle M, Pickard J. Preventable deaths in multiple trauma: review of deaths at Sunnybrook Medical Centre Trauma Unit. Can J Surg 1983; 26: 20-23.

22 Meguro K, Tator $\mathrm{CH}$. Effect of multiple trauma on mortality and neurological recovery after spinal cord or cauda equina injury. Neurol Med Chir (Tokyo) 1988; 28: 34-41.

23 Tator $\mathrm{CH}$ et al. Management of acute spinal cord injuries. Can J Surg 1984; 27: 289-294.

24 Tator $\mathrm{CH}$ et al. Complications and costs of management of acute spinal cord injury. Paraplegia 1993; 31: 700-714.

25 Frankel HL et al. Value of postural reduction in the initial management of closed injuries of the spine with paraplegia and tetraplegia. I. Paraplegia 1969; 7: 179-192.

26 Fehlings MG, Tator $\mathrm{CH}$. A review of experimental models of acute spinal cord injury. In: Illis L (ed). Spinal Cord Dysfunction. Oxford Univ Press: Oxford, 1988, pp 3-43.

27 Guha A, Tator CH, Endrenyi L, Piper I. Decompression of the spinal cord improves recovery after acute experimental spinal cord compression injury. Paraplegia 1987; 25: 324-339.

28 Tator $\mathrm{CH}$ et al. Comparison of surgical and conservative management in 208 patients with acute spinal cord injury. Can J Neurol Sci 1987; 14: 60-69.

29 Department of National Health and Welfare, Ottawa, Canada. Guidelines for Establishing Standards for Units/Services/Programs in Institutions. Spinal Cord Injury Programs. Ministry of Supply and Services, Ottawa, Canada, 1986.

30 McNally NH. Report of the Project Team on the Management of Spinal Cord Injuries. Province of Ontario, Ministry of Health, Personal Care Division, June 1975. 